\title{
From Interpersonal Violence to Institutionalized Discrimination: Documenting and Assessing the Impact of Islamophobia on Muslim Americans
}

\author{
Naheed Ahmed*, Sandra C. Quinn ${ }^{\dagger}$, Rupali J. Limaye ${ }^{\ddagger}$, and Suleiman Khan ${ }^{\S}$
}

\begin{abstract}
Muslims and people perceived as Muslims face Islamophobia, defined as an "irrational fear of, aversion to, or discrimination against Islam or people who practice Islam." Reports of hate crimes motivated by Islamophobia have increased, as have other forms of Islamophobia, such as workplace discrimination. This qualitative study examined the impact of Islamophobia on Muslim Americans, ranging from school and workplace discrimination to policies that target Muslims, such as government surveillance. The objectives of this study were to document the spectrum of Islamophobia in the U.S. and to assess the impact of Islamophobia on Muslim Americans using components of grounded theory, qualitative data collection, and analysis. Using a semi-structured interview guide, a total of 40 participants ( 20 women, 20 men) were interviewed about self-reported experiences with Islamophobia and responses to bias incidents. Participants self-identified as Muslim, were at least 18 years of age, and represented various ethnic groups. Interviews were audio recorded, transcribed, and analyzed using Nvivo 12. Findings indicate that Islamophobia and xenophobia are significant sources of long-term stress. Participants discussed physical assaults in public locations, vandalism at their homes, persistent questioning regarding their country of origin, and verbal harassment in the form of derogatory terms. Islamophobia in the U.S. is multifaceted and a significant source of stress for Muslim Americans. Findings from this study and others on this topic highlight the need for interventions to support Muslim Americans.
\end{abstract}

Keywords

United States $\bullet$ Muslim Americans $•$ Islamophobia $・$ discrimination

\footnotetext{
*University of Maryland, nahmed12@umd.edu

${ }^{\dagger}$ University of Maryland, scquinn@umd.edu

(iD https://orcid.org/0000-0002-3258-4595

†ohns Hopkins University, rlimaye@jhu.edu

(D) https://orcid.org/0000-0002-3883-9720

§suli.k@live.com
}

doi: 10.3998/jmmh.119

Conflicts of interest:

The authors have no conflicts of interest to disclose. 


\section{Introduction}

Although Islamophobia, defined as an "irrational fear of, aversion to, or discrimination against Islam or people who practice Islam," dates to the earliest entry of Muslims to the United States, its escalation in the past twenty years is evident in the workplace, local communities, health care settings, schools, and government policies (Beydoun, 2019; Merriam-Webster, 2019; Ogan, Willnat, Pennington, \& Bashir, 2014). Examples of Islamophobia range from discrimination in employment, street harassment, and bullying, to government surveillance and profiling of Muslims. Hate crimes against Muslims increased in the months after the September 11 attacks and during the contentious 2016 presidential election (Austin, 1997; Diouf, 2013; Disha, Cavendish, \& King, 2011; FBI, 2017). Despite years of increasing Islamophobia in the U.S., our understanding of this particular form of discrimination is limited, in particular the various forms of Islamophobia and the impact of Islamophobia on Muslim Americans. To fill this critical gap in the literature, this qualitative study examined how Islamophobia manifests in the U.S. and how Muslim Americans are coping with increased Islamophobia.

\section{Literature Review}

\section{Islamophobia in the U.S.}

Muslims and non-Muslims alike have experienced interpersonal and institutionalized forms of Islamophobia, in the form of street harassment, physical and verbal attacks, discrimination in schools and workplaces, and government surveillance and profiling (Disha, Cavendish, \& King, 2011). Interpersonal Islamophobia refers to discriminatory acts by individuals, whereas institutionalized Islamophobia refers to discriminatory policies and laws (Oskooii, 2016). Existing studies have revealed Muslim Americans deal with street harassment, such as verbal and physical attacks in public locations (Nadal et al., 2012; Aroian, 2012; Muedini, 2009; Peek, 2003). Research on Muslim American students indicate instances of discrimination from classmates, high school teachers, and college professors (Aroian, 2012; Nasir \&Al-Amin, 2006; Peek, 2003).

Legal records and qualitative studies demonstrate the discrimination Muslim Americans have dealt with in regard to employment. The U.S. Equal Employment Opportunity Commission (EEOC) reported a 250\% increase in discrimination claims from Muslim Americans after the September 11 attacks (EEOC, 2018). Employment discrimination against Muslim, Sikh, Middle Eastern, and South Asian communities continued in the years after September 11, leading to the EEOC creating a specific code to track employment discrimination against these groups and filing approximately 90 lawsuits on behalf of complainants (EEOC, 2018). Examples of employment discrimination include businesses refusing to hire Muslim women who wear hijab, overt Islamophobic comments in oral and written evaluation from colleagues and supervisors (e.g., called "Muslim Taliban"), being denied promotions and opportunities to join lucrative projects, and, in some cases, termination of employment (Malos, 2010).

Along with school and workplace discrimination motivated by Islamophobia, the FBI has documented increases in hate crimes against Muslims and people perceived as Muslims in the first two decades of the 21 st century. Hate crimes are defined as criminal acts motivated by religious-based bias against an individual, residence, school, or place of worship; dramatic increases occurred both after $9 / 11$ and as the result of bigoted, inflammatory rhetoric in the 2016 election (481 reported incidents in 2001 compared to 28 in 2000 and 307 in 2016 compared to 154 in 2014, respectively; Disha et al., 2011; FBI, 2017; Kishi, 2016). In some extreme instances, Muslims and people perceived as Muslims have died as a result of hate crimes. Sikh men, many 
whom do not cut their hair and wear turbans for religious reasons, have been murdered because their attackers believed them to be Muslim (Ahluwalia \& Pellettiere, 2010).

There are many incidents of hate crimes against mosques and legal challenges and community opposition to the construction of mosques in the U.S. (Iyer, 2017). Opposition to mosques has taken the form of discriminatory zoning laws, local elected officials voting against requests to construct mosques, and community members organizing legal challenges to the establishment of mosques (Ernst, 2013). The American Civil Liberties Union asserts that opposition to mosques is often presented as concern regarding traffic, parking, and noise, but these complaints are cover for anti-Muslim and anti-Islam sentiments (ACLU, 2018a). Some Muslim communities, who have faced opposition to requests to construct mosques, have turned to the U.S. Department of Justice (DOJ) to enforce the 2000 Religious Land Use and Institutionalized Persons Act, which protects religious institutions from discriminatory zoning and landmarking laws (DOJ, 2018).

The increase in hate crimes against Muslims and people perceived as Muslims has coincided with the implementation of federal policies that have led to increased government surveillance and profiling of Muslims in the U.S. (Alimahomed-Wilson, 2018; O'Connor \& Jahan, 2014). Examples of these policies include the Patriot Act (2001), National Security-Entry-Registration Systems (2002), the FBI's Terrorist Screening Database, the Transportation and Security Administration's Screening Passengers Observation Techniques program, Countering Violent Extremism Program (2014), and Executive Order 13769 "Protecting the Nation from Foreign Terrorist Entry into the United States" (2017; Aden \& Whitehead, 2001; O'Connor \& Jahan, 2014; Shora, 2003).

The Patriot Act, passed shortly after the September 11, 2001 attacks, broadened the powers of law enforcement agencies to monitor phone and Internet activity and financial transactions (Aden \& Whitehead, 2001). Surveillance of non-residents from Arab and Muslim-majority countries increased during this time as well. The National Security Entry-Exit Registration Systems (NSEER) was implemented under the newly created Department of Homeland Security (DHS) in 2002 (Shora, 2003). NSEER required non-resident males, 16 and older, to register in-person with Immigration and Naturalization Services (Shora, 2003). The registration process involved being photographed and fingerprinted, and registrants were required to exit and enter through specific ports of the U.S. (Shora, 2003).

Other methods enacted by the federal government ostensibly to prevent terrorist attacks include enhanced security measures at airports. The FBI collected the names of individuals suspected of being involved in terrorist activities on a list called the "Terrorist Screening Database" or "watchlist" that contains an estimated one million names (OIG, 2007). This list is used during screening procedures for visas, air travel, and other activities according to the FBI (FBI, 2018b). Along with the use of the "watchlist", the Transportation and Security Administration (TSA) launched the "Screening Passengers Observation Techniques (SPOT)" to identify suspicious travelers (DHS, 2017). Travelers ensnared within these security policies have experienced invasive secondary searches, missed flights from security delays, and in some cases, airlines have prevented them from boarding even though they cleared TSA security (Akram \& Johnson, 2001).

Government surveillance of Muslims has extended to mosques and schools, most recently through the Countering Violent Extremism (CVE) program established in 2014 under the DHS's purview (Selim, 2016). CVE is a federal program that partners with community leaders (e.g., religious leaders), social services, and local law enforcement agencies to prevent violent extremism (Szmania \& Fincher, 2017). While the program purports to prevent all forms of extremism, implementation of the policy has focused solely on American Muslim communities 
(Patel \& Koushik, 2017). For example, pilot programs implemented in Minneapolis, Boston, Los Angeles, and Montgomery County, Maryland only focused on Muslim Americans (Patel \& German, 2015). Critics of the CVE program have raised concerns regarding the perpetuation of negative stereotypes regarding Muslims and Islam, and profiling of Muslim school children (Patel \& Koushik, 2017). Other federal surveillance efforts have included the deployment of informants to infiltrate mosques, where informants have spied on mosque attendees and in some cases enticed mosque members to carry out domestic terrorist acts (Al-Faham, 2021; Szpunar, 2017).

Finally, a recent example of government sanctioned Islamophobia is "Executive Order 13769 - Protecting the Nation from Foreign Terrorist Entry into the United States" also known as the "Muslim Travel Ban", which banned travelers from Iran, Iraq, Libya, Somalia, Sudan, Syria, North Korea, Venezuela, and Yemen (White House, 2017). The order included travelers with valid visas to work and study in the U.S., resulting in the detainment of 750 travelers and 60,000 visas being revoked (Jouvenal, Weiner, \& Marimow, 2017; Lind, 2018). The first iteration of the ban contained an exception for Christian travelers from these countries, but in response to legal challenges, revised executive orders were issued to include all travelers regardless of their faith (ACLU, 2018b). On June 26, 2017, the U.S. Supreme Court upheld the travel ban in a 5-4 decision, the majority citing the president's authority to issue the ban and dismissing the claim that the order is based on religious bias (ACLU, 2018b).

These examples illustrate the multifaceted and interconnected nature of Islamophobia in the U.S., ranging from hate crimes against Muslims and people perceived as Muslims to government policies that have led to increased surveillance and profiling of Muslim Americans. Linked with these domains of Islamophobia are media platforms that perpetuate negative stereotypes of Muslims and Islam, such as news stories that only report on Muslims in relation to terrorism, and entertainment shows (e.g., television, movies) that cast Muslim or Arab characters as the villains in plot lines (Alsultany, 2012). Interpersonal and community violence coupled with Islamophobic government policies and media representations have contributed to an environment where Islam is perceived as antithetical to American values, and Muslims are viewed as inherently violent and suspect (Alimahomed-Wilson, 2018; Lajevardi \& Oskooii, 2018).

\section{Gaps in Literature}

Despite years of increasing hate crimes against Muslims and government policies that have contributed to the surveillance and profiling of Muslims, our understanding of how Islamophobia in the U.S. manifests and impacts Muslim Americans is limited. A few qualitative studies have examined experiences with Islamophobia, but the study samples were either small or focused on a particular group of Muslims, such as college students or a specific ethnic group. Given the diversity of Muslims in relation to nativity, visibility, and race/ethnicity, there is a critical need for qualitative studies that examine the lived experiences of Muslims in-depth. This data is vital for understanding the varying form of Islamophobia in the U.S. and the impact of Islamophobia on Muslims.

\section{Theoretical Frameworks}

A hybrid theoretical approach informed this study, drawing upon relevant concepts from Prather and colleague's socioecological model for understanding the role of discrimination, and Harrell's racism-related classification system (Harrell, 2000; Prather et al., 2016). First, the socioecological model provided a broad framework for understanding the multilevel impact 
of discrimination on health. Examples of discrimination-related health factors at each level of the socioecological model include knowledge, skills, attitudes at the individual level, family and social networks at the family/interpersonal level, where an individual lives and works at the neighborhood/community level, and institutionalized discrimination at the societal level (Prather et al., 2016). These multilevel sources of discrimination-related stress may take the form of daily stressors, lack of social support, and institutionalized discrimination, the cumulative effects of which may shape an individual's level of stress and resulting adverse health outcomes (Prather et al., 2016).

Finally, Harrell's conceptualization of racism-related stress provides additional discrimination domains to consider in delineating the various forms of Islamophobia. Harrell classifies discriminatory events according to three primary sources of stress: episodic stress (short-term), daily hassles (microaggressions), and chronic stress (historical and collective) (Harrell, 2000). These stress typologies account for the various levels at which discrimination-related stress is perceived, including environmental and contextual factors that may shape an individual's experiences (Harrell, 2000). Harrel's six categories of racism-related stress are:

1. Racism-related life events - Significant, but time limited events (e.g., workplace discrimination);

2. Vicarious racism experiences - Observation and reporting of discriminatory incidents (e.g., attack on family member or friend);

3. Daily racism micro-stressors - Daily reminders of people's reactions to your race/ ethnicity (e.g., being followed or observed in public);

4. Chronic-contextual stress - Social, political, and institutionalized inequalities (e.g., unequal resource allocation);

5. Collective experiences - Cultural-symbolic and sociopolitical manifestations of racism (e.g., lack of political representation);

6. and Transgenerational transmission - Stress of historical oppression passed onto each generation (e.g., legacy of historical discrimination).

Collectively, domains from each of these models align with Islamophobia in terms of the various levels at which Islamophobia-related discrimination operates, the individual and collective aspects of Islamophobia, and the socio-political environment, which has contributed to and normalized Islamophobia in the U.S. Given the multifaceted nature of Islamophobia in the U.S., including but not limited to xenophobic elements, government policies that target Muslims, and hate crimes against Muslims and mosques, a hybrid theoretical approach is necessary for studying Islamophobia.

\section{Methods}

\section{Data Collection Methods}

A semi-structured interview guide was used with participants, covering conceptualization of Islamophobia, perception and treatment of Muslims in the U.S., personal and vicarious experiences with discrimination, and response to discrimination. Follow-up questions were asked during the course of interviews. Interviews were conducted in-person and via phone/Internet, depending on the geographic location of the participant and which interview method was convenient for the participant. Interviews lasted between 30 and 60 minutes, and were conducted from 2017 to 2019. 


\section{Recruitment}

Potential participants were identified through outreach to South Asian and Muslim organizations, mosques, student groups at universities, and snowball sampling methods. The research team leveraged their personal contacts to recruit potential participants from their social and professional networks (family members were excluded). At the end of each interview, the principal investigator (PI) asked participants for individuals in their social network who might be interested in being interviewed. Participants did not receive any incentives for their participation, but were told their responses would assist with documenting and measuring discriminatory experiences among Muslim Americans.

\section{Ethics}

University of Maryland, College Park IRB approval for this study was issued on August 28, 2017. Participants were given an electronic or hard copy of the consent document to review prior to the interview. The consent document detailed the study objectives, potential risks, free confidential counseling services available locally and a nationwide suicide prevention hotline, and contact information for the PI and the University of Maryland, College Park IRB office. Participants were informed that their participation is voluntary and that they may refuse to answer any questions or end the interview with no repercussions to them. Interviews were audio recorded with the permission of participants.

\section{Participants}

Forty Muslim American participants, who were at least 18 years old, were interviewed $(\mathrm{N}=40)$. The sample included foreign- and native-born Muslim Americans. All interviews were conducted in English. It was expected that data saturation, the point at which no new data is being collected, would be achieved with a sample of 40 (Goldberg \& Allen, 2015).

\section{Data Analysis}

Interviews were transcribed and analyzed for common themes. The analysis was guided by components of grounded theory, specifically open coding where codes were formulated after reviewing transcripts, writing memos after reviewing each code output, and double coding whereby two researchers coded interviews independently and then met to discuss any coding discrepancies (Charmaz, 2000). The software program Nvivo 12 was used to organize and analyze data. Results were written by primary themes. Descriptive text ("most", "more", "a few", "the majority", "some") was used to explain findings. It should be noted that this language is intended to describe trends and nuances in data, and should not be interpreted as statistical inferences.

\section{Results}

\section{Participant Characteristics}

Demographic information on the sample is detailed in Table 1. The age of participants ranged from 20 to 74 years old, with a median age of 62, and an average age of 24 . Highest education level completed varied among participants. The majority have advanced degrees: 16 have a master's degree, 7 a doctorate or professional degree, and 9 hold a bachelor's degree. The majority of participants are Sunni Muslims $(\mathrm{n}=24)$ and 11 have no affiliation. Most participants were born in the U.S. $(n=24)$. Participants represented a range of ethnic groups, including Pakistani 
Table 1. Participant Demographics $(\mathrm{N}=40)$

\begin{tabular}{|c|c|c|c|c|c|}
\hline Age & & & Country of Birth & $\mathbf{N}$ & $\%$ \\
\hline Range & $20-74$ & & USA & 24 & 60 \\
\hline Median & 31 & & Pakistan & 5 & 12.5 \\
\hline Mean & 37.22 & & Iran & 3 & 7.5 \\
\hline \multirow[t]{2}{*}{ Standard Deviation } & 15.07 & & Bangladesh & 3 & 7.5 \\
\hline & & & Jordan & 2 & 5 \\
\hline Sex & $\mathbf{N}$ & $\%$ & Saudi Arabia & 1 & 2.5 \\
\hline Female & 20 & 50 & Ethiopia & 1 & 2.5 \\
\hline Male & 20 & 50 & Egypt & 1 & 2.5 \\
\hline Education & $\mathbf{N}$ & $\%$ & Ethnicity & $\mathbf{N}$ & $\%$ \\
\hline Diploma & 1 & 2.5 & Pakistani & 8 & 20 \\
\hline High School & 4 & 10 & Bangladeshi & 7 & 17.5 \\
\hline Associate's & 1 & 2.5 & Mixed & 5 & 12.5 \\
\hline Bachelor's & 9 & 22.5 & Afghan & 4 & 10 \\
\hline Some graduate & 2 & 5 & Syrian & 3 & 7.5 \\
\hline Master's & 16 & 40 & Palestinian & 2 & 5 \\
\hline \multirow[t]{2}{*}{ Doctorate/Professional } & 7 & 17.5 & Arab & 2 & 5 \\
\hline & & & Persian & 2 & 5 \\
\hline Religion & $\mathbf{N}$ & $\%$ & White & 2 & 5 \\
\hline Muslim - Sunni & 24 & 60 & Indonesian & 1 & 2.5 \\
\hline Muslim & 11 & 27.5 & Ethiopian & 1 & 2.5 \\
\hline Muslim - Shiite & 3 & 7.5 & Indian & 1 & 2.5 \\
\hline Muslim - Hanafi & 1 & 2.5 & Egyptian & 1 & 2.5 \\
\hline Muslim - Ahmadiyya & 1 & 2.5 & Black & 1 & 2.5 \\
\hline
\end{tabular}

( $n=9)$, Bangladeshi $(n=7)$, mixed ethnicity $(n=5)$, Afghan $(n=4)$, and Syrian $(n=3)$. The majority were visibly Muslim ( $\mathrm{n}=33$ ), meaning they have adopted an Islamic style of dress (e.g., hijab, abaya, thawb) or for men have grown a beard, which may be for religious or other reasons. Participant information is provided for each reported quote, signified by the interview number, sex of the participant, and a " $(V)$ " is used to denote visible Muslims.

\section{Direct Experiences with Islamophobia}

When asked if they had ever directly experienced Islamophobia, most participants said they had encountered some form of anti-Muslim discrimination. These incidents included a range of discriminatory acts, including verbal and physical harassment, issues when traveling by air or crossing international borders, profiling by law enforcement agencies, road rage acts, and physical assault. Some encounters involved non-Muslims asking questions about Islam, some 
of which was asked out of curiosity, but some situations were uncomfortable. Experiences with Islamophobia took place in a variety of locations, such as schools, offices, homes, and stores.

\section{Non-Verbal Interactions}

A number of participants spoke of uncomfortable public interactions, where no verbal comments were made, but the other person seemed deliberately rude in their non-verbal cues, such as their facial expression. While participants could not definitively state if the interaction was motivated by anti-Muslim bias, they questioned why a stranger would openly glare at them or a store employee would intentionally not greet them. One example is as follows:

"Another incident where you suspect that you're being mistreated because you're Muslim, but you won't know for sure because they're not as you know direct at . . . you know they're not calling you, you know a terrorist or telling you to go back home ... they're just you know giving you a weird look or mistreating you with a ... you know ... grocery store or something like that."

Interview 6, Female (V)

\section{Verbal Incidents}

Several participants spoke of incidents in public locations, such as walking on a public street or shopping in a grocery store, where strangers made discriminatory comments toward them. These comments ranged from derogatory terms used for Muslims to xenophobic remarks.

One participant, who is white, has worn hijab in the past and no longer wears one, recounted the difference in her treatment. She has been told to "go back to her country" and called a "terrorist" on public streets when wearing hijab. Now that she no longer wears hijab, she has noticed a difference in how she is treated. However, in conversations with non-Muslims, when she discloses she is Muslim, she notices a perceptible shift in people's demeanor toward her:

"I did wear hijab for 14 years, um, and I took it off, now, wow, almost three years ago . . . because I could just see in my own life, the way that, um, the situation is getting worse and worse, and, you know, I could just feel the hostility. . . . um, when I did wear hijab. I mean, even now, interestingly, it's fascinating to see how people treat me (laughing) like before they find out I'm Muslim, and then afterwards. Um, so again, I mean, it's just, as soon as you say that word, Muslim, you can literally see all of this, like, you know, implicit bias rising up in people, um, and even just their physical reaction to me changing. Um, when I did wear hijab, the situation was uh, was much more obvious. I mean, I had people scream at me on the street, call me a terrorist. Tell me to go back to my own country, um, which is totally bizarre, because I was born and raised here. I'm also a convert. Um, so, so seeing all that, you know, very upsetting, but also eye opening about the real state of racism. . . . . for people. Um, and just the way that .. . Like you can be walking down the street, and people will whisper horrible things to you, so that nobody else around them, you know, can hear it. . . . . leaving, you know, leaving me just kinda standing there like, "Did I just imagine that this person called me a terrorist?"

Interview 11, Female 


\section{Comments about Islam and Muslims}

In addition to verbal harassment, some participants encountered pointed questioning from non-Muslims regarding Islam and Muslims. This line of questioning appeared to be out of genuine curiosity for some participants, but others perceived the questioners as trying to prove a point or confirm stereotypes about Islam:

"Yeah. I mean, the ... the biggest things, like, it depends on the person. I know sometimes you'll get, like, the things that stick out the most, I would say. Like those shock value facts about Islam. So like, it's . . . they would say, like, "Oh, but the.. the Prophet had, like, $\mathrm{x}$ amount of wives, right?" That kind of thing. Or it's like, "Oh, you're allowed to have four wives in Islam." You know? So it's like ... they really focus in on the, like, the ... the things that really don't fall into place in the contemporary, like, Western culture, right? And, like, you know, you can't just go out and, like, marry four people right now, right? So. . . (laughs) So, yeah. So there's things like that. Um, I mean, some people, though, it's not.. it's like . . . you know, some people will ask you, like, they're like, more into the culture and are genuinely interested in it. They actually are, you know . . . they just really want to find out more about your religion or so, you know. I find that people who grew up with more multicultural, um, friends and stuff like that, they tend to be the most approachable and . . you know, when they ask you questions you can tell they're not trying to, like, you know, just like regurgitate facts they found from, like, whatever news source they have, you know? Like they'll say, "Oh, like, what's the difference between, like, halal meat and kosher meat?"

Interview 40, Male (V)

\section{Academic Institutions}

Several participants shared incidents that took place in educational institutions ranging from elementary schools to universities. These encounters occurred with fellow students and in some cases with teachers and professors. The types of discrimination participants encountered included stereotypes regarding Muslims, bullying from other students, and discriminatory comments regarding Muslims. In the period after the September 11 attacks, several participants spoke of name calling and bullying from other students because of their background. For one participant, he faced not only bullying from other students, but these incidents took place in front of teachers, who did nothing to stop the other students:

"I mean after 911 I think that there are a lot of us that had certain stories uh, about you know, "is Osama your uncle? Or are you a terrorist?" That happened. "And the Qur'an says you know, $x, y$, and z;" some sort of um, references to how we're [inaudible] and just like violent and belligerent by nature. But um, those were, those were things that I had, that had occurred right after 911, um and in my classroom uh, and with teachers present right. So there is this, condoning of behaviors that I think adults shouldn't be condoning." 
Participants shared negative experiences at the university level, especially for visible Muslim women, who encountered stereotypes regarding Muslim women and felt their peers assumed they were not bright. A few participants said they felt their fellow students were reluctant to associate with them or work with them, until they demonstrated they were intelligent and capable students.

"Even when I was an undergraduate student for the first few weeks students would not sit beside me and once they found out about my grades and they know I'm okay in class, they start agreeing to be a part of my group. That's always the case, as an undergraduate student I felt like once they know that I'm a good student, I can help them with the projects and I can contribute to their learning that when they become kind of like more . . . at ease and start talking to me and working with me."

Interview 5, Female (V)

\section{Workplace}

Participants spoke of incidents in the workplace, where they were singled out for their physical appearance (e.g., Islamic clothing, skin tone), "foreign" sounding name, or their faith. One participant, who is visibly Muslim, spoke of several incidents at an internship with a local government agency, where her colleagues assumed English was her second language and would share stereotypes with her regarding Islam, such as women having no rights. Another participant shared an incident that took place on the day of the September 11 attacks. She was watching the news with her colleagues, when one of her colleagues asked her if she was related to Osama bin Laden. Other workplace incidents include a participant, who is a healthcare provider. $\mathrm{He}$ has had several patients make discriminatory and demeaning comments toward him and refuse treatment from him.

"I work in a [health] setting, so I mean I've had people say "I don't want no fucking raghead to be my [medical provider]..I don't-I don't, I don't want no towelhead, uh, go back to Iraq, go back to Afghanistan. I'm not gonna see you, you sand nigger. . ."

Interview 7, Male (V)

\section{Media Narratives}

Several participants spoke of media depictions of Muslims and new stories on Muslims, which many found negative overall in how Muslims are represented. For example, one participant who was young when September 11 happened, said he grew up with Islamophobic news stories and thought this type of news content was normal. Several participants discussed the bias of how media outlets report on Muslims, in particular violent incidents involving Muslims. When attacks are carried out by Muslims, the media dissects the religious motivations behind the attack, in effect contributing to a reductive analysis of the perpetrator, which is not extended to attacks by non-Muslims.

"It's upsetting to see a lot of spotlight isn't given to Muslim voices on Muslim issues. You'll see, which is not to say that an attack done by a Muslim extremist is 
a Muslim issue. But if there is an attack by a Muslim extremist, someone claiming to be a Muslim, and there's a segment on the news about it they'll bring in all these people, not Muslims, to discuss it and how it relates to Islam and how it relates to Muslims. And if you're going to talk about us and stigmatizing us and reducing us to these horrible stereotypes and you're not going to even include us in the conversation? I mean what is that? It's like that's not fair at all."

Interview 2, Female

\section{Physical Threats and Assaults}

A few participants shared painful experiences where they were physically threatened or assaulted in public locations. In one example, a participant shared a story of his family's home being vandalized shortly after the September 11 attacks. A dead raccoon was left on his family's doorstep and although no note was left with the carcass, the participant and his family believed the vandalism was motivated by bigotry.

A visible female participant spoke of a painful experience at a local grocery store during the U.S. invasion of Iraq after September 11. She was shopping for groceries, when she suddenly felt a sharp pain in her chest area. She looked up to see a man glaring at her while remaining silent, who had hit her in the chest. She was stunned by the attack and left the store without telling anyone.

"And I remember going into supermarket one day and I had this..I turned around and there was this and of course I'm wearing my hijab, right? And I glimpsed around and there was this big guy with a red face. His face was so red. You know..it looked like a tomato. And I felt this horrible ... horrible pain in my chest and I couldn't breathe. He just elbowed me..you know he just elbowed me with his elbow, you know. I couldn't breathe. You know, I couldn't breathe. And I just remember this.. uh..you know when you're frozen? You're so shocked..you're frozen..you don't know what to say? I..just..you know..all that..just tears were come down my eyes and my cheeks. Uh..and.. I just left.”

Interview 1, Female (V)

\section{Road Incidents}

Some participants had incidents on the road, where they felt they were singled out because they are visibly Muslim. The encounters ranged from gestures to objects being thrown at them. One participant said she was driving with her mom and passengers in a car driving next to them on the highway made an explosion gesture at them.

Another participant recounted a road rage incident where he was in the car with his wife and infant daughter. They were searching for a house in a residential neighborhood, when the participant noticed a car following them. Thinking that the other driver was in a hurry, he pulled over to the side, but the other driver stopped next to them. The driver, an elderly white woman, started yelling and cursing at the participant and his family. She told them to "go back to their country" and threw a clipboard at them.

"And when we pulled over, you know, they rolled their window down, and it was, you know, an old, uh, American lady. She had to be probably in her 60s plus, and 
just yelling at us, cussing at us. And, uh, she was like, "Go back to your country, wherever you're from," all this stuff."

Interview 30, Male (V)

\section{Traveling while Muslim}

Many participants spoke of issues traveling, such as extra security screenings at airports, being denied boarding passes, and for some, delays with re-entering the U.S. Several participants said that these travel hassles happen regularly enough for them to know they were not randomly selected. They have noticed that travelers without a Muslim name or Muslim appearance seem to get through security quicker than them.

One participant, who has been stopped several times at international borders and in airports, said when he asked government agents why he was stopped during one incident, he was told he shares a name with a "bad guy".

"Um, as an adult, um I would say rarely, probably. I mean, I think the obvious also other example would be I've continually been stopped and had trouble at airports and borders. Like, I have been stopped at the [country name] border for five or six hours for no real reason, presumably because I'm Muslim or have a Muslim name, or whatever. And I asked them, in certain cases, although not all of them, when I ask why I've been stopped, they'll say it's because you share a name with a bad guy. (Laughs) That was their statement."

Interview 31, Male (V)

This same participant said he's been picked for full searches at airports, which involves a full pat down and his boarding pass not being released through online check-in procedures, but instead he is required to check-in physically at the airport. Other incidents have involved agents asking about his relatives living abroad in terms of their occupations. He attributes these extra security protocols to sharing a name with someone on a government watch list and because his family is from a Muslim-majority country.

A participant, who was traveling by air for a work trip, shared an incident where security questioned why she was carrying her work laptop with her, even though agents had just let her colleague pass without any issues. Her colleague was waiting for her and upon noticing what was happening, stepped in to tell agents their questions were inappropriate.

"I was traveling with my colleague who is a white female, um and I did get the, a flag from TSA uh for my laptop. So they had a lot of concerns and questions about as to why I'm traveling with a laptop for business. And they did a lot of, "What do you do for a living?", a lot of interrogating, a lot of questions, and kind of delaying me in the process. Um, luckily my colleague jumped in saying, you know, "This is really inappropriate." And so, uh, we just kind of went through the questions and then he, he let me go."

Interview 13 , Female (V)

One participant spoke of a time when he was traveling to his brother's wedding and was almost prevented from boarding the plane. The airline system would not accept his boarding pass even though he had cleared airport security. After pleading with the gate agent to let him board, a manager was able to override the system, and he was allowed to board. 
"I have been almost prevented from getting on a plane for no apparent reason kind of thing. Uh..literally when I was going to my brother's wedding and um..this was the most recent time..and uh I was I got through security fine. And then they held me up at the gate. And they said you can't get on. And I said why not? And they said we need you to wait here, you're holding up the line. And then literally right before..just a few minutes before the final call, I was pleading with the guy to let me on and the guy's manager came over and I don't know what she did in the system but she cleared my boarding pass and let me on."

Interview 3, Male (V)

\section{Government Policies}

Along with issues traveling by air and crossing international borders, participants shared other forms of government surveillance and profiling of Muslims. Examples include the Executive Order 13769 (Muslim travel ban), surveillance of mosques, and the NSEER program, which required foreign males from Muslim majority countries to register with the federal government. A participant, whose family is from a country included in the Muslim ban, said her family members are struggling to find refuge in nearby countries because they can no longer obtain U.S. visas.

"Initially when the problem started they were able to seek refuge in nearby countries and some of the Middle East and some other foreign countries. But the US specifically I feel like once Trump became president has labeled a list of countries, such as [country part of Muslim travel ban], that are predominantly Muslim countries. That can no longer even get a visa to the United States just because they are Muslim.”

Interview 14, Female (V)

Another participant spoke of an incident where the FBI came to his home to question him. He learned the FBI had been conducting surveillance at the mosque he attended and FBI agents were visiting the homes of mosque attendees.

"I forgot to mention that not too long after that, the FBI came to my house and paid me a, oh, it wasn't just me, but a lot of people. Like, and just, "Just say," you know. And, I'm like, "What? I didn't. . .," like, it just felt very, um, like criminalized. Like, I'm just, I'm Muslim, so you're coming . . . You know, like why? You know, so. It felt very, like, invasive, you know. Yeah, I'm just a guy trying to, you know, feed my family, and do. I'm not involved in any crazy stuff."

Interview 25, Male (V)

A participant, who relocated to the U.S. for work, recounted how upon entering the U.S. he was required to register and be fingerprinted under the NSEER program.

"I remember the first time I came to U.S. and I was, obviously I had my [Muslim majority country] passport, and they took me away for three hours to interview me and put all my fingers, digital fingers, so that was one of the issue."

Interview 38, Male 
This mandatory registration system helped during an encounter with immigration officials. He was traveling to visit a family member and was stopped during an immigration check on a highway. The immigration officials arrested him and took him to jail because he did not have his passport with him. He was driving with a U.S. driver's license, but immigration agents would not accept this form of identification. While in the holding cell, the participant repeatedly told immigration officials his information had already been collected by the U.S. government. After agents located his name in their database, he was released. This encounter left the participant shaken and scared, given how quickly he was taken into custody and the aggressive manner in which agents interacted with him.

\section{Response to Direct Experiences with Islamophobia}

Responses to discriminatory events varied among participants. Some ignored comments or actions, while others were assertive in terms of countering hateful comments and in some cases reporting incidents to the police. The emotions of participants varied across the different incidents as well, ranging from sadness to anger, and for some a combination of feelings.

Participants spoke of feeling unwelcome and their frustration with being pre-judged by others, which for many was a significant source of stress given that the U.S. is their home.

"It just makes you feel very unwelcome. Uh..you know not sure..can you. . . . be safe is what I guess a lot of people would say. Is your personal safety guaranteed in this situation? But um..even..uh I would say for me I kind of don't worry much at all about my safety perhaps as much as I should but um..this feeling of being like unwelcomed and just not being sure if my neighbors want to talk to [me]. Um, should I just stay isolated in my house?"

Interview 3, Male (V)

Several participants spoke of the anger they felt after repeat incidents, where they were singled out for their faith. Some spoke of the pain of not being accepted as American and their accomplishments and contributions being dismissed, and in some cases their rights as U.S. citizens being denied to them.

"There's a lot of anger inside of you. Because, um, the, the emotions that I feel definitely anger- rises to the top. Uh, a level of fear is definitely present. Because then you all of a sudden, you, you worked so hard to claim your American identity. And you realize how quickly it can be taken from you. I mean, I've had incidents at airports like this. And you realize how marginalized you can become. How, even though we have certain rights. It feels like they're very fragile. Um, and, uh, and then it's hard to feel truly American when other Americans don't want to accept your Americanness."

Interview 32, Male (V)

Others spoke of withdrawing or concealing their identity because of repeat incidents, where they felt singled out or attacked for their faith. Some spoke of not bringing up their faith in conversations and some female participants reported taking of their hijabs, so they are not as easily identifiable as Muslim.

"I don't necessarily bring up religion, you know, in the workplace, or otherwise." Interview 2, Female 
Fear regarding their personal safety has contributed to heightened vigilance, in terms of participants reporting greater awareness of their surroundings, carrying personal protection with them (e.g., pepper spray), and taking precautions when traveling (e.g., making sure their phones are fully charged, signing up for air travel clearance programs).

"Yeah, so I, because of those incidences, um I've gotten Global Entry."

Interview 13, Female (V)

Some participants felt hopeful about the future in relation to Muslims being eventually accepted and are actively engaged in efforts to counter anti-Muslim discrimination, including initiatives to counter Islamophobia.

"I'm not silent, I'm not your token, I'm not going to just stand by while you say and think things that I know aren't true."

Interview 24, Female (V)

\section{Discussion}

Study findings highlight the multiple encounters with Islamophobia participants faced, ranging from non-verbal interactions to physical assaults. Islamophobic incidents took place in a variety of locations, including public streets, stores, academic institutions, and workplaces. Participants spoke of negative non-verbal interactions, where they noticed strangers openly glaring at them or store employees refusing to greet them, which participants said left them feeling unsettled and unwelcomed. Verbal incidents reported by participants, included being called derogatory slurs used for Muslims.

Islamophobic comments were not limited to strangers, as several participants spoke of colleagues, classmates, and teachers engaging in similar behaviors. Participants, who were children at the time of the September 11 attacks, spoke of their classmates bullying them, such as calling them terrorists or accusing them of being connected to Osama bin Laden. Comments regarding connections to bin Laden were also made by adults, as recounted by a participant who had a colleague ask her if she was related to bin Laden. Other uncomfortable exchanges involved questions about participants' faith based on misconceptions and stereotypes regarding Muslims and Islam. While some of these questions were asked out of genuine curiosity and a desire to learn about Islam, participants said some conversations felt like an interrogation. The latter situations left participants feeling attacked and defensive, as they were asked to explain and defend the faith of all Muslims.

Islamophobic incidents in the workplace, such as comments about Muslims and terrorism, represent the casualness of Islamophobia in everyday conversations. The saturation of unfavorable media coverage regarding Muslims has contributed to the perception of Muslims as untrustworthy and suspicion that all Muslims are a threat. These exchanges reflect the pervasiveness of negative stereotypes associated with Islam and Muslims, which shape daily interactions for participants, who are viewed as representatives of their faith and burdened with dispelling myths regarding Muslims.

Along with non-verbal and verbal incidents, participants reported physical encounters, in which strangers assaulted them in public locations. The escalation of Islamophobic incidents to physical attacks is troubling, as it demonstrates a willingness on the part of some to act on their bigotry through violence. Some participants recounted road rage incidents, where other 
drivers were aggressive with them in terms of cutting them off, yelling at them, and in some cases throwing objectives at them.

These direct experiences of Islamophobia mirror the levels of discrimination delineated in Prather and colleagues' socioecological model and Harrel's racism-related stress model (Harrell, 2000; Prather et al., 2016). Areas of alignment between the study results and these models include the interpersonal (family and social networks) and community (environmental factors) levels of the socioecological model, and the racism-related life events (significant but time limited events), vicarious racism experiences (observation of discriminatory incidents), and daily racism microstressors (daily reminders of people's reactions to your race/ethnicity) domains of the racism-related stress model (Harrell, 2000; Prather et al., 2016).

Moving beyond interpersonal forms of discrimination, participants detailed institutionalized Islamophobia, such as profiling at airports, visits from law enforcement agents, and registering as part of a federal registry for foreign-males from Muslim-majority countries. Participants spoke of delays when traveling by plane, including additional security screenings, being required to check-in in-person for flights, and in some cases delays with boarding their plane after clearing airport security. Other forms of institutionalized Islamophobia included surveillance of Muslim communities and profiling of visitors from Muslim-majority countries.

These examples of institutionalized forms of Islamophobia align with the society level (institutionalized discrimination) of Prather and colleagues' socioecological levels of discrimination and the chronic contextual stress (social, political, institutional inequalities) category of Harrell's racism-related stress model (Harrell, 2000; Prather et al., 2016). Similar to how racial discrimination has been enacted against and experienced by marginalized groups, Islamophobia in the U.S. manifests in various forms, ranging from interpersonal incidents to Islamophobic government policies. As stated by study participants and researchers of Islamophobia, Muslims have been "racialized", whereby stereotypes and attributes have been ascribed to Muslims, which have resulted in Muslims being "otherized" and being treated in a discriminatory manner (Galonnier, 2015; Joshi, 2006).

Furthermore, Muslims face other forms of discrimination given the intersectional nature of discrimination and the diversity of Muslims. Gendered Islamophobia has affected both male and female participants. A number of female participants spoke of incidents where they felt they were mistreated or dismissed because they are Muslim women. For example, several female participants spoke of acquaintances or colleagues assuming they are slow or oppressed. These incidents not only reflect stereotypes associated with Muslim women, but the perception of women as easy targets and visible Muslim women being singled out for harassment. Overall, visible male and female participants felt their physical appearance played a role in the harassment and profiling they have faced. In terms of Islamophobic government policies, such as additional security measures when traveling and government surveillance, there were more reports of this type of Islamophobia among male participants, which represent a perception of Muslim men as dangerous and suspicious. Gendered Islamophobia has contributed to Muslim men and women experiencing varying types of Islamophobia, specifically interpersonal incidents against Muslim women and institutionalized forms of Islamophobia targeting Muslim men.

Another facet of Islamophobia is its overlap with xenophobia, in that several participants spoke of encounters where they were targets of xenophobic comments (e.g., "go back to your country"), including participants born in the U.S. These incidents were cited by some participants as the racialization of Muslims, particularly for White converts to Islam who faced discrimination for the first time in their lives after converting. For participants of color, many discussed 
instances where their citizenship status or country of origin were questioned, despite being born and raised in the U.S., otherwise known as the perpetual foreigner stereotype (Huynh, Devos, \& Smalarz, 2011). These participants cited their skin tone and names as contributing factors behind this particular line of questioning. Participants found these exchanges frustrating because although they may have dual cultural identities, they consider themselves American, and find it exasperating when others question their Americanness.

Given the range of Islamophobic experiences, and the intersectional nature of discrimination they faced, the response to these incidents varied as well. Participants expressed a spectrum of emotions when speaking about discriminatory events, including sadness, frustration, anger, and fear. The cumulative effects of multiple incidents left many participants anxious and fatigued in terms of being vigilant for future attacks, and awareness that their position as Muslim Americans is precarious. Participants spoke of taking precautionary measures to prevent incidents, such as maintaining a fully charged cell phone when traveling in rural areas or avoiding certain locations where they might be unwelcomed. This response of heightened vigilance after discriminatory encounters is common, as victims feel unsafe and wish to prevent future incidents (Barnes \& Ephross, 1994). Other reactions among participants involved withdrawing and concealing their Muslim identity. A few female participants said they stopped wearing hijab because of the mistreatment they received as visible Muslims. Some participants said they considered removing their hijabs to feel safe and accepted. For participants, who are not visibly Muslim, avoiding conversations about their faith or religious practices was their approach to hiding their identity from others. Others said their experiences with Islamophobia have motivated them to become politically engaged, such as registering voters, organizing awareness events regarding Islamophobia, and advocating on behalf of Muslim Americans. The range of responses to Islamophobia, from withdrawing and vigilance in public spaces to activism, have been documented in other studies on Muslim Americans and discrimination (Al-Faham, 2021; Hobbs \& Lajevardi, 2018)

\section{Strengths and Limitations}

This study is not without limitations. Based on the recruitment method employed, we relied on a convenience sample and snowball sampling for this study. As qualitative research is a perspective-based method, the results from our study are not representative. While we sought to limit bias, we must acknowledge that the interviewers could have inadvertently biased interview discussions, as the content was quite emotionally charged at times. Additionally, due to potential fears related to legal status and other forms of persecution, self-reporting bias is likely present. Despite these limitations, we were able to recruit a heterogeneous range of participants. To our knowledge, this is one of the first studies to explore Islamophobia across a wide range of participants from a number of ethnic/racial backgrounds. We believe that we were able to elicit a diverse range of perspectives.

\section{Conclusion}

These findings speak to the need for more research on Islamophobia in the U.S. and the impact of Islamophobia, as there are significant gaps in the literature. Muslim Americans have faced years of increasing Islamophobia, but few studies have examined the health implications of Islamophobia. We know from research with other minority groups, specifically African Americans, that exposure to discrimination is associated with a range of adverse health outcomes, from psychological distress to medical disorders, which has yet to be fully examined 
among Muslim Americans (Samari et al., 2018). Previous studies have established a link between Islamophobia and poor mental health, but our knowledge of associations with other health outcomes is limited (Amer \& Bagasra, 2013).

In addition to studying the varying forms and implications of Islamophobia, it is critical to examine potential buffers to Islamophobia, so as to design effective interventions to support Muslim communities. Examples of potential protective factors, include social support (e.g., community, family, friends), faith (e.g., practices and teachings), coping strategies (e.g., exercise, hobbies), mental health services, self-efficacy (e.g., confidence in one's ability to overcome challenges), and a strong identity (e.g., ethnic, religious; Lewis, Cogburn, \& Williams, 2015). The evidence on potential buffers to discrimination is limited, but it is unlikely that one factor alone is sufficient, and a combination of protective elements may be needed for an individual to withstand discrimination. For example, a strong identity has been shown to buffer the effects of discrimination, but it may also increase an individual's exposure to bias incidents. A possible solution to this conundrum could be increasing self-efficacy, along with pride in identity, so individuals feel confident in their ability to withstand discrimination and reduce the stigma associated with their identity (Cristini, Scacchi, Perkins, Santinello, \& Vieno, 2011). Muslim Americans have dealt with Islamophobia for decades without any substantial support or understanding of their experiences. The time for improving our knowledge of the health implications of Islamophobia, and designing and implementing interventions to support Muslim Americans is long overdue.

\section{References}

ACLU. (2018a). Nationwide Anti-Mosque Activity. Retrieved December 6, 2018, from https://www. aclu.org/issues/national-security/discriminatory-profiling/nationwide-anti-mosque-activity

ACLU. (2018b). Timeline of Muslim Ban. Retrieved December 13, 2018, from https://www.aclu-wa. org/pages/timeline-muslim-ban

Aden, S., \& Whitehead, J. (2001). Forfeiting Enduring Freedom for Homeland Security: A Constitutional Analysis of the USA Patriot Act and the Justice Department's Anti-Terrorism Initiatives. Am. UL Rev., 5I(6), 1081-1133.

Ahluwalia, M., \& Pellettiere, L. (2010). Sikh men post-9/11: Misidentification, discrimination, and coping. Asian American Journal of Psychology.

Akram, S. M., \& Johnson, K. R. (2001). Race, Civil Rights, and Immigration Law after September 11, 2001: The Targeting of Arabs and Muslims. New York University Annual Survey of American Law, 58 .

Alimahomed-Wilson, S. (2018). When the FBI Knocks: Racialized State Surveillance of Muslims. Critical Sociology.

Al-Faham, H. (2021). Researching American Muslims: A Case Study of Surveillance and Racialized State Control. Perspectives on Politics, 1-16.

Alsultany, E. (2012). Arabs and Muslims in the Media: Race and Representation after 9/Ir. New York City: New York University.

Amer, M. M., \& Bagasra, A. (2013). Psychological research with Muslim Americans in the age of Islamophobia: Trends, challenges, and recommendations. American Psychologist, $68(3), 134$. 
Aroian, K. J. (2012). Discrimination Against Muslim American Adolescents. The Journal of School Nursing, 28(3), 206-213.

Austin, A. D. (1997). African Muslims in antebellum America: transatlantic stories and spiritual struggles. Routledge.

Beydoun, K. A. (2019). American Islamophobia: understanding the roots and rise of fear. University of California Press.

Cristini, F., Scacchi, L., Perkins, D. D., Santinello, M., \& Vieno, A. (2011). The influence of discrimination on immigrant adolescents' depressive symptoms: What buffers its detrimental effects? Psychosocial Intervention, 2o(3), 243-253.

Diouf, S. (2013). Servants of Allah: African Muslims Enslaved in the Americas (15th Anniv). New York City: NYU.

Disha, I., Cavendish, J. C., \& King, R. D. (2011). Historical Events and Spaces of Hate: Hate Crimes against Arabs and Muslims in Post-9/11 America. Social Problems, 58(1), 21-46.

DOJ. (2018). Religious Land Use And Institutionalized Persons Act. Retrieved December 11, 2018, from https://www.justice.gov/crt/religious-land-use-and-institutionalized-persons-act

EEOC. (2018). What You Should Know about the EEOC and Religious and National Origin Discrimination Involving the Muslim, Sikh, Arab, Middle Eastern and South Asian Communities. Retrieved January 4, 2019, from https://www.eeoc.gov/eeoc/newsroom/wysk/religion_national_ origin_9-11.cfm

Ernst, C. (2013). Islamophobia in America: The Anatomy of Intolerance. New York City: Palgrave MacMillan

FBI. (2017). 2016 Hate Crime Statistics. Retrieved February 7, 2018, from https://ucr.fbi.gov/hatecrime/2016

FBI. (2018). Terrorist Screening Center.

Galonnier, J. (2015). The racialization of Muslims in France and the United States: Some insights from white converts to Islam. Social Compass, 62(4), 570-583.

Harrell, S. P. (2000). A multidimensional conceptualization of racism-related stress: Implications for the well-being of people of color. American Journal of Orthopsychiatry, 7o(1), 42-57.

Hobbs, W., \& Lajevardi, N. (2019). Effects of divisive political campaigns on the day-to-day segregation of arab and muslim Americans. American Political Science Review, Irз(1), 270-276.

Huynh, Q. L., Devos, T., \& Smalarz, L. (2011). Perpetual foreigner in one's ow n land: Potential implications for identity and psychological adjustment. Journal of Social and Clinical Psychology, 3о(2), 133-162.

Iyer, D. (2017). We Too Sing America. The New Press.

Joshi, P., Islam, S., Pais, P., Reddy, S., Dorairaj, P., Kazmi, K., . . Yusuf, S. (2007). Risk Factors for Early Myocardial Infarction in South Asians Compared With Individuals in Other Countries. $J A M A, 297(3), 286$.

Jouvenal, J., Weiner, R., \& Marimow, A. E. (2017, February 3). Justice Dept. lawyer says 100,000 visas revoked under travel ban; State Dept. says about 60,000. The Washington Post.

Kishi, K. (2016). Anti-Muslim assaults reach 9/11-era levels, FBI data show | Pew Research Center. Retrieved April 21, 2017, from http://www.pewresearch.org/fact-tank/2016/11/21/anti-muslimassaults-reach-911-era-levels-fbi-data-show/ 
Lajevardi, N., \& Oskooii, K. A. (2018). Old-fashioned racism, contemporary islamophobia, and the isolation of Muslim Americans in the age of Trump. Journal of Race, Ethnicity and Politics, 3 (1), 112-152.

Lewis, T. T., Cogburn, C. D., \& Williams, D. R. (2015). Self-Reported Experiences of Discrimination and Health: Scientific Advances, Ongoing Controversies, and Emerging Issues. Annual Review of Clinical Psychology, II(1), 407-440.

Lind, D. (2018, June 26). How Trump's travel ban became normal. Vox.

Malos, S. (2010). Post-9/11 Backlash in the Workplace: Employer Liability for Discrimination against Arab- and Muslim- Americans Based on Religion or National Origin. Employee Responsibilities and Rights Journal, 22(4), 297-310.

Merriam-Webster. (2019). Definition of Islamophobia. Retrieved August 26, 2019, from https://www. merriam-webster.com/dictionary/Islamophobia

Muedini, F. (2009). Muslim American College Youth: Attitudes and Responses Five Years After 9/11. The Muslim World, 99, 39-59.

Nadal, K. L., Griffin, K. E., Hamit, S., Leon, J., Tobio, M., \& Rivera, D. P. (2012). Subtle and overt forms of Islamophobia: Microaggressions toward Muslim Americans. Journal of Muslim Mental Health, 6(2). http://dx.doi.org/10.3998/jmmh.10381607.0006.203

Nasir, N. S., \& Al-Amin, J. (2006). Creating Identity-Safe Spaces on College Campuses for Muslim Students. Change, 38(2), 22-27.

O'Connor, A. J.. J. F., \& Jahan, F. (2014). Under Surveillance and Overwrought: American Muslims' Emotional and Behavioral Responses to Government Surveillance. Journal of Muslim Mental Health, 8(1).

Ogan, C., Willnat, L., Pennington, R., \& Bashir, M. (2014). The rise of anti-Muslim prejudice. International Communication Gazette, 76(1), 27-46. https://doi.org/10.1177/1748048513504048

OIG. (2007). Follow-Up Audit of the Terrorist Screening Center. Washington, D.C.

Oskooii, K. A. (2016). How discrimination impacts sociopolitical behavior: A multidimensional perspective. Political Psychology, 37(5), 613-640.

Patel, F., \& German, M. (2015). Countering Violent Extremism: Myths and Fact. Retrieved from https:// www.brennancenter.org/sites/default/files/analysis/102915 Final CVE Fact Sheet.pdf

Patel, F., \& Koushik, M. (2017). Countering Violent Extremism. New York City. Retrieved from https:// www.brennancenter.org/publication/countering-violent-extremism

Peek, L. A. (2003). Reactions and Response: Muslim Students' Experiences on New York City Campuses Post 9/11. Journal of Muslim Minority Affairs, 23 (2).

Prather, C., Fuller, T. R., Marshall, K. J., \& Jeffries, W. L. (2016). The Impact of Racism on the Sexual and Reproductive Health of African American Women. Journal of Women's Health, 25(7), 664-671.

Samari, G., Alcalá, H. E., \& Sharif, M. Z. (2018). Islamophobia, health, and public health: a systematic literature review. American journal of public health, $108(6)$, e1-e9.

Selim, G. (2016). Approaches for Countering Violent Extremism at Home and Abroad. The Annals of the American Academy of Political and Social Science, 668(1), 94-101.

Shora, K. (2003). National Security Entry Exit Registration System (NSEERS). Cardozo Public Law, Policy E Ethics Journal, 73, 73-80.

Szmania, S., \& Fincher, P. (2017). Countering Violent Extremism Online and Offline. Criminology \& Public Policy, r6(1), 119-125. 
Szpunar, P. M. (2017). Premediating predisposition: informants, entrapment, and connectivity in counterterrorism. Critical Studies in Media Communication, 34(4), 371-385.

White House. Executive Order Protecting The Nation From Foreign Terrorist Entry Into The United States, The White House (2017). Retrieved from http://www.nnirr.org/drupal/sites/default/files/ trump_executive_order_muslim_ban_2.0.pdf 